\title{
ESR Studies on Characteristic Physio-chemical Effects of Some Irradiated Antibiotics
}

\author{
Saleh M. Abdou ${ }^{(1) \#}$ and S. Ebraheem ${ }^{(2)}$ \\ ${ }^{(1)}$ Radiation Physics Department, NCRRT, Atomic Energy Authority (AEA), Cairo, \\ Egypt; ${ }^{(2)}$ Radiation Protection Department, NCRRT, Atomic Energy Authority (AEA), \\ Cairo, Egypt.
}

\begin{abstract}
$\mathbf{M}$ OST of the characteristic chemical effects of the irradiated solid drugs are not accurately detected by the conventional tests such as ultra violet spectro-photometry and melting point technique. Sterilization using gamma irradiation is a desirable alternative for the thermosensitive drugs. Antibiotics samples were -irradiated at room temperature with doses ranging from $2 \mathrm{kGy}$ up to $25 \mathrm{kGy}$. Electron Spine Resonance (ESR) measurements were applied on four types of antibiotics; Amoxycillin, Ampicillin, Dalacin and Spiramycin (AMX, AMP, DAL and SPI). ESR results exhibited the impact of irradiation and storage parameters on the nature and concentration of the trapped radicals. The radical concentration is directly proportional to the ESR peak height signal also depending on the absorbed dose delivered to the antibiotic samples. The obtained information about the irradiated radiolytic products was found to verify the radical mechanisms. This information may be used to detect an irradiation treatment on such pharmaceuticals.
\end{abstract}

Keywords : Drug sterilization, ESR, Ionizing radiation, Gamma irradiation.

\section{Introduction}

Ionizing radiation is one of the most favorable methods for sterilization of several active ingredients in drugs or drug delivery systems containing these substances. The sterilized radiation dose (as a choice) is based on the initial bioburden, but $25 \mathrm{kGy}$ is the maximal admitted dose for the radiosterilization. High penetrating power, isothermal character of the procedure, that allow a suitable treatment for heat-sensitive materials and sterilization in the final package are the major advantages of gamma rays. This mode of sterilization is also cheaper than lyophylization, micro-filtration and filling steps under aseptic conditions. Moreover, homogeneous sterilization using gamma-irradiation is useful for packaged products, thus avoiding further risk of microbe contamination (Bartolotta et al., 2005).

The Commission of the European Communities has introduced some guidelines about the use of ionizing radiation in the pharmaceuticals manufacture. The knowledge of the irradiation effects on the stability of materials and formation of degradation products are required
(Commission of the European Communities, 1990). For this reason, accurate analyses are required for the sterilization method using ionizing radiation for medicinal products, to ensure that the active ingredient has not been modified and no toxic products have been produced. Nevertheless, the characteristic chemical effects that were produced due to irradiation of solid drugs are not detected by classical tests. In the reverse arrangement, radiolysis is the best way to study radical mechanisms in solid.

Electron spin resonance (ESR) is a very sensitive method for the detection of free radicals. ESR can be used for studying the radiolysis mechanism (Crucq, 1994) or for detection of irradiated drugs (Zeegers et al., 1993 and Gibella et al., 2000) as already used for foodstuffs irradiated at very low dose (Raffi \& Stocker, 1996). ESR study of simple amino acids has been made in order to identify quantitatively and qualitatively the radiation-induced radicals in amino acid powders (Talbi et al., 2004). One of the problems of the radiosterilization is the production of new radiolytic yields during the irradiation process (Barbarin \& Tilquin, 2001). Therefore, the major

"Corresponding author email: salehabdou03@yahoo.com 
attention in radiosterilization is to determine and to characterize the chemical and physical changes originating from high-energy radiation (Hayes et al., 1980; Bussey et al., 1982 and YektaOzer et al., 2013). They have already shown the suitability of ESR for the detection of the induced radical in some specific irradiated antibiotics.

In the absence of suitable analytical detection methods, the attention was focused on the ESR technique as a tool for identification (Onori et al., 1996). Dose-response curve for the integral ESR absorption spectrum and the associated radicals were generated for antibiotic azithromycin samples irradiated at various gamma radiation doses up to $25 \mathrm{kGy}$.

The radiosterilization produces new products which could be potentially toxic. (Calis et al., 2002 and Yoshioka et al. 1995). Historical studies, on the decay curve of the radicals, resulted in the possibility of estimating the initial dose of irradiation (Bartolotta et al., 2005). The biochemical properties of intermediates generated in drugs following gamma sterilization are serious if they are formed in a considerable number and therefore reduce the therapeutic properties of the pharmaceuticals (Wilezynski et al., 2014).

The present work deals with studying the induced effect of gamma irradiation on the different antibiotic types called; AMX, AMP, DAL and SPI (Amoxycillin, Ampicillin, Dalacin, and Spiramycin). The mechanisms of radicals'<smiles>CC1(C)S[C@@H](NC(=O)[C@@H](N)c2ccc(O)cc2)C(=O)N1C(=O)O</smiles>

Amoxicillin

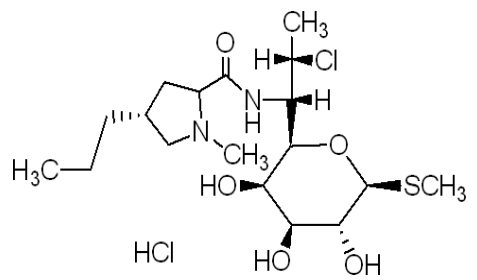

Dalacin $\mathrm{C}^{*}$ formation were discussed as well as the produced species due to the irradiation. Also, the radiation response of each one was evaluated. The effect of the storage time on the concentration of the radical trapped in the matrixes was also evaluated.

\section{Materials and Method}

ESR measurements are applied on four types of antibiotics: Amoxicillin (Molecular Formula: C16H19N3O5S (AMX); Molecular Weight: 365.40); Ampicillin (Molecular Formula C16H19N3O4S (AMP); Molecular Weight 349.40); Dalacin [CLINDAMYCIN HCL] (Molecular Formula: C18H33ClN2O5S $\cdot \mathrm{HCl}$ (DAL); Molecular Weight: 461.44) and Spirex (Spiramycin; Molecular Formula C30H32N2O14 (SPI); Molecular Weight 646.65). Figure 1 presents the chemical structure for the drugs under use.

The irradiation was carried out at room temperature in the presence of air with radiation doses of $2 \mathrm{kGy}, 5 \mathrm{kGy}, 10 \mathrm{kGy}, 15 \mathrm{kGy}, 20 \mathrm{kGy}$, and $25 \mathrm{kGy}$. Gamma irradiation of the samples has been carried out by means of CO-60 gamma source "4000 A, Indian gamma chamber" at a dose rate of $1.912 \mathrm{kGy} / \mathrm{h}$.

ESR signals were recorded at room temperature using a Bruker X- band spectrometer under the following conditions: Microwave power $=1.008$ $\mathrm{mW}$, modulation amplitude $=4.00 \mathrm{G}$, modulation frequency $=100 \mathrm{kHz}$. The spectrum was recorded as the first derivative signal.<smiles>CC1(C)S[C@H]2[C@H](NC(=O)[C@@H](N)c3ccccc3)C(=O)N2[C@H]1C(=O)O</smiles>

Ampicillin

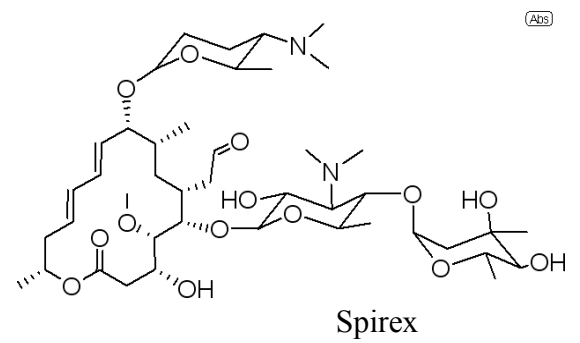

Spirex

Fig. 1. The chemical structure for the drugs under use. 


\section{Results and Discussions}

If the drug is dispersed in a solid drug delivery system, the components of formulation may be altered by radiation as a consequence of radiolysis, thus affecting the drug release from the dosage form and hence, its safety.

Antibiotics samples, namely, Amoxycillin, Ampicillin, Dalacin, and Spiramycin (AMX, AMP, DAL and SPI) were irradiated at room temperature at doses ranging from $2 \mathrm{kGy}$ up to $25 \mathrm{kGy}$. Electron Spine Resonance (ESR) measurements were applied on the four types of antibiotics. ESR results exhibited the influence of irradiation and storage parameters on the nature and concentration of the trapped radicals.

\section{ESR spectra}

During irradiation of solid drugs, free radicals are formed and trapped in the matrix. These radicals are studied by Electron Spin Resonance (ESR) which is a very sensitive technique. The ESR signal is detected immediately after irradiation and a part of the free radicals produced survives at room temperature for a long time.

The samples irradiated at room temperature show ESR spectra (Fig. 2, 3, 4, 5), not very well resolved: mainly singlet with partial doublet (AMX, AMP), doublet (DAL), singlet with some disturbances (SPI); moreover the spectra depend on the radiation dose ranged from 5 to $25 \mathrm{kGy}$. The radical concentrations corresponding to the first derivative were recorded and it will be proportional to the peak heights of the recorded spectrum.

From the figures one can see, the unirradiated samples generally present no EPR-signal; very small singlet may be observed in some cases (SPI, AMX and AMP), due to sunlight-UV irradiation. The recording conditions (temperature, microwave power and time after irradiation) may have an influence on the resolution of the spectra before and after irradiation.

Figures 2, 3, 4 and 5 present the EPR-Spectra of the unirradiated and irradiated samples recorded at different absorbed doses.

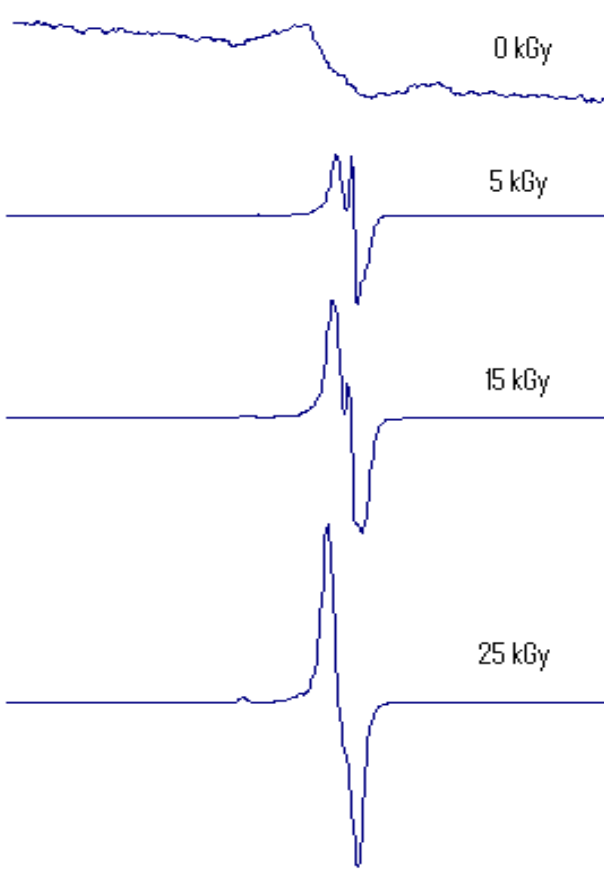

Fig. 2. AMP unirradiated and irradiated samples.

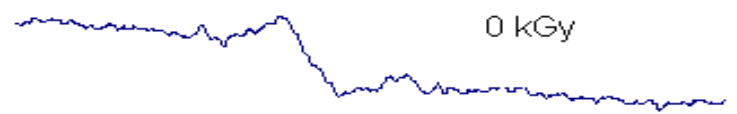

$5 \mathrm{kGy}$

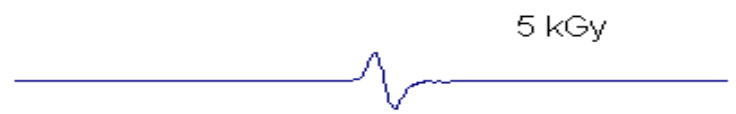

$15 \mathrm{kGy}$

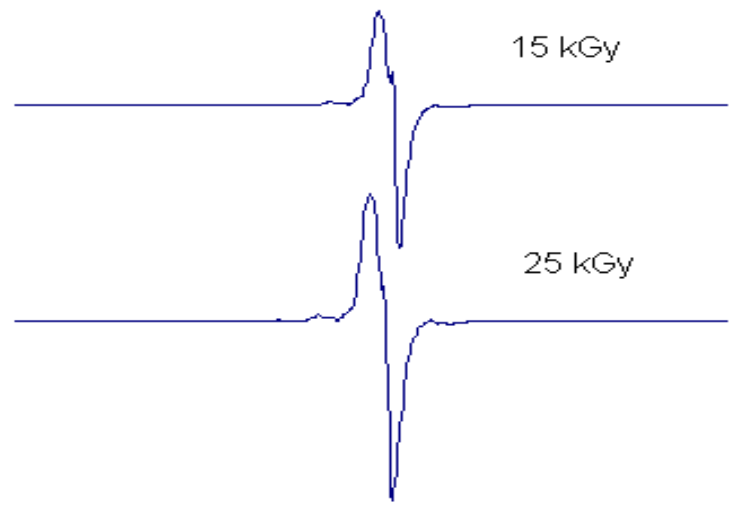

Fig. 3. AMX unirradiated and irradiated samples. 


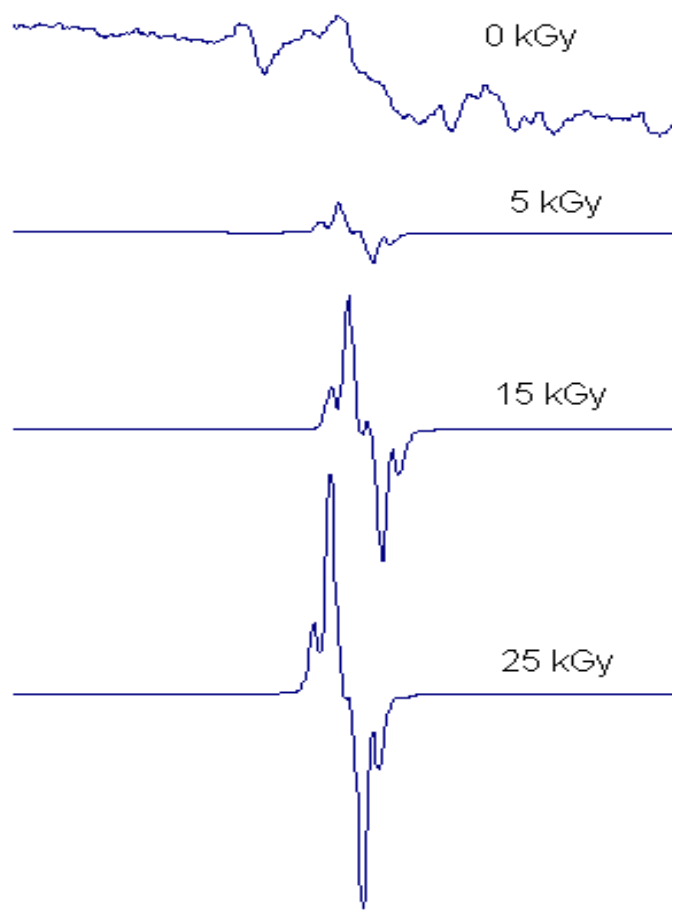

Fig. 4. DAL unirradiated and irradiated samples.
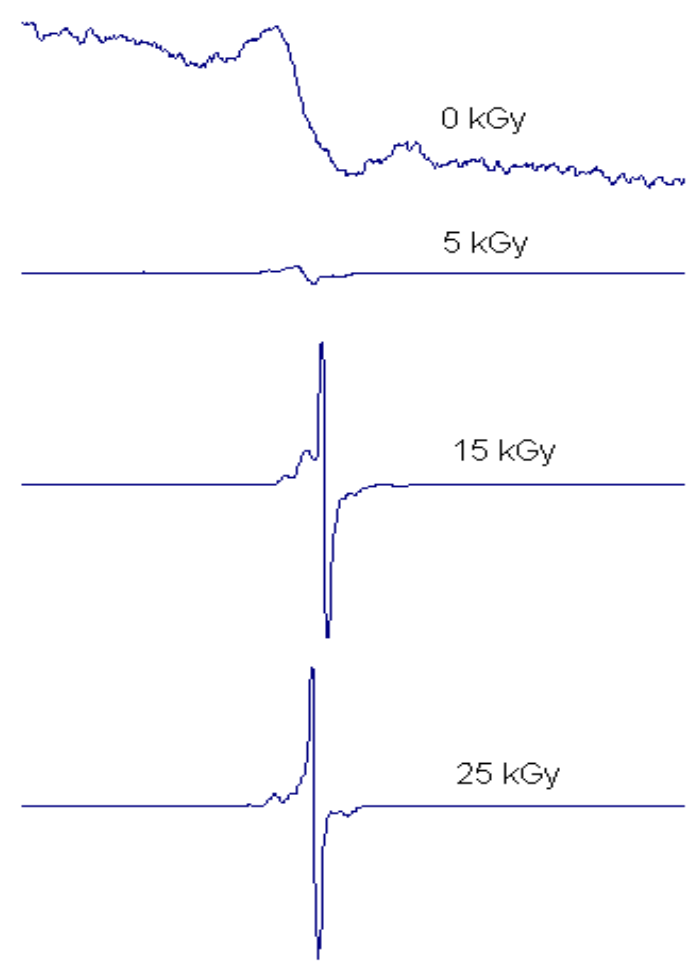

Fig. 5. SPI unirradiated and irradiated samples.

\section{Radical formation mechanism}

AMX and AMP spectra show two singlets, one singlet is attributed to the radical $\mathrm{C}\left(\mathrm{CH}_{3}\right)_{2} \mathrm{COOH}$ and the strong singlet is due to aminoxyl radicals. The DAL spectrum is a doublet due to the formation of two strong radicals, one on both nucleolus. SPI has a complicated way of session which affects the EPR spectrum, because of that it has a strong singlet beside some disturbance for a small amount of different type of radicals trapped in the solid matrix. The mechanism of radical formation, produced due to irradiation of molecules, could be directly or by neutralization of radical-cations.



Excited molecules may decompose into radicals by rupture of chemical bonds.

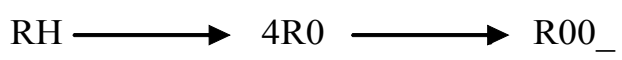

However, fragment radicals do not diffuse in solid matrices "cage effect" and immediate germinate termination reactions are possible. If the original radical cation escapes immediate neutralization, a very important ion molecule reaction may give radicals.

$\mathrm{RH}$

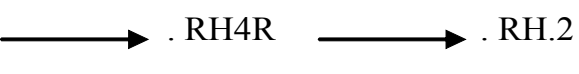

RH.

. $\mathrm{RH} 4 \mathrm{r}$

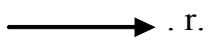

This mechanism is very important with polar molecules like $\mathrm{H} 2 \mathrm{O}$ where an electron is trapped far from the germinate cation. The cation is neutralized $(\mathrm{RH}+2+\mathrm{e})$ when electrons are ejected from their traps; some luminescence occurs and are recorded with increasing the temperature (thermo luminescence) of the irradiated samples.

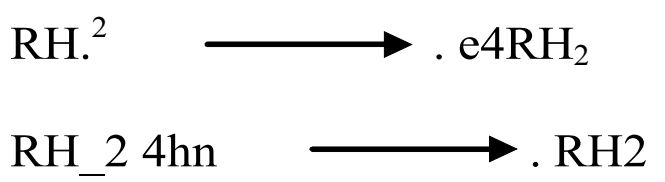

Excited molecules and radical cations are produced by the direct interaction with the ionizing radiation and are localized along the track in regions of high local concentration (spurs). So the radicals are also formed in spurs, and the 
kinetic, must take the effects of non homogeneous formation of the species into consideration.

After applying radiosterilization process on the antibiotics, ESR spectra confirm the production of ionic radicals in the gamma irradiated samples due to the direct effect of radiation on the bonds and benzene ring.

\section{Response curves}

The dose response curves of the four antibiotics (AMX, AMP, DAL and SPI) irradiated at different doses ranged from 2 to $25 \mathrm{kGy}$ are shown in Fig. 6.

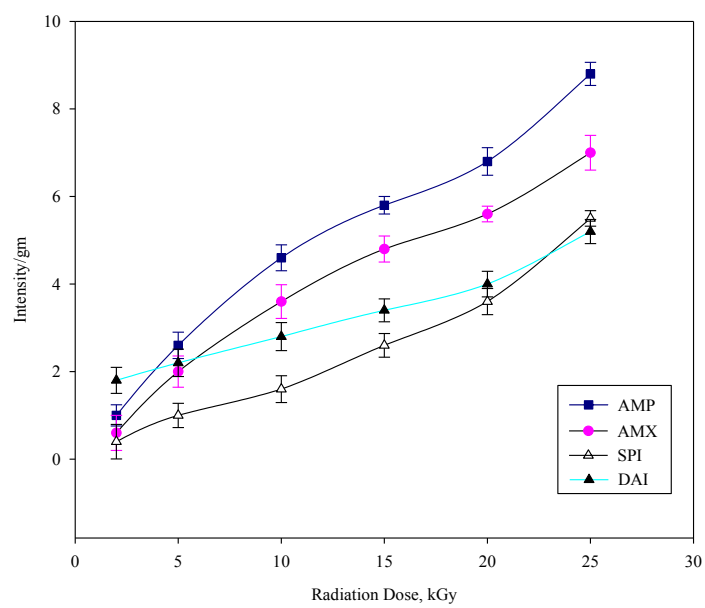

Fig. 6. Shows the dose response curves of four antibiotics (AMX, AMP, DAL and SPI) irradiated to different dose ranged from 2 to 25 kGy.

The dose response curves were established in terms of change in EPR signal measured at constant microwave power per unit weight, intensity.gm ${ }^{-1}$, against the absorbed dose of the unirradiated and irradiated samples, respectively. Each point on the dose response curve represents the mean average of five measurements (five samples irradiated to the same dose) with the calculated uncertainty of $\pm 7 \%$ at $1 \sigma$. It can be noticed that all curves show the same trend. The response of the antibiotics was found to be ranging from 2 to $25 \mathrm{kGy}$, proportionally increases with the dose increase. This was attributed to the increase of radical concentration due to the irradiation by gamma rays.

\section{Conclusion}

Sterilization is necessary for many pharmaceutical products to ensure their safe and effective use. Pharmaceutical industry sterilization by gamma irradiation has been commonly used as an effective method to sterilize pharmaceutical products. The increase of radical concentration due to the irradiation by gamma rays reflects changes in the physical properties of the antibiotic samples during the sterilization process. Also reflects the increase of possible of producing a side product could be played as a toxic compound later on.

\section{References}

Barbarin, N. and Tilquin, B. (2001) Study of nonvolatile degradation compounds produced by radiosterilization of cefotaxime. Radiat. Phys. Chem. 60, 359-367.

Bartolotta, A., D’Oca, M.C., Campisi, M., De Caro, V., Giandalia, G., Giannola, L.I., Brai, M. and Calderaro, E. (2005) European Journal of Pharmaceutics and biopharmaceutics, 59, 139-146.

Bussey, D.M., Kane, M.P. and Tsuji, K. (1982) Sterilization of corticosteroids by Co-60 irradiation. J. Parenter Sci. Technol. 37, 51-54.

Calis, S., Bozdag, S. and Kas, H.S. (2002) Influence of irradiation sterilization on poly(lactideco-glycolide) microspheres containing antiinflammatory drugs. Il Farmaco, 57, 55-62.

Commission of the European Communities (1990) CPMP working party on Quality of Medicinal Products. Ionizing irradiation in the Manifacture of Medicinal Products. III/9109.

Crucq, A-S. (1994) Etude de mecanismesradicalaires de medicaments irradies. Chim. Nouv. 12, 1356-1359.

Gibella, M., Crucq, A-S., Tilquin, B., Stoker, P., Lesgards, G. and Raffi, J. (2000) Electron spin resonance studies of some irradiated pharmaceuticals. Radiation Physics and Chemistry, 58(1), 69-76.

Hayes, R., Fletcher, G. and Davies, D.J.G. (1980) The effect of ionizing radiation on beclamethazonedipropionate. J. Pharm. Pharmacol. 32, 48-50.

Onori, S., Pantaloni, M., Fattibene, P., Ciranni Signoretti, E., Valvo, L. and Santucci, M. (1996) ESR identification of irradiated antibiotics: Cephalosporins. Applied Radiation and Isotopes, 47(11/12), 1569-1572. 
Raffi, J. and Stocker, P. (1996) Electron paramagnetic resonance detection of irradiated foodstuffs. Applied Magnetic Resonance, 10, 357-373.

Talbi, S., Raffi, J., Aréna, S., Colombani, J., Piccerelle, P., Prinderre, P. and Dolo, J.M. (2004) EPR study of gamma induced radicals in amino acid powders, Spectrochimica Acta Part A: Molecular and Biomolecular Spectroscopy, 60(6), 1335-1341.

Wilczyński, S., Pilawa, B., Koprowski, R., Wróbel, Z., Ptaszkiewicz, M., Swakoń, J. and Olko, P. (2014) Free radicals properties of gamma-irradiated penicillin-derived antibiotics: Piperacillin, ampicillin, and crystalline penicillin. Radiat Environ Biophys. 53(1), 203-210.
Yekta Özer, A., Turker, S., Çolak, S., Korkmaz, M., Kiliç, E. and Özalp, M. (2013) The effects of gamma irradiation on diclofenac sodium, liposome and niosome ingredients for rheumatoid arthritis. Interv. Med. Appl. Sci. 5(3), 122-130.

Yoshioka, S., Aso, Y. and Kojima, S. (1995) Drug release from poly(DL-lactide) microspheres controlled by g-irradiation. J. Control Release, 37, 263-267.

Zeegers, F., Crucq, A-S., Gibella, M. and Tilquin, B. (1993) Radiolyse et radiosterilisation des medicaments. J. Chim. Phys. 90, 1029-1040.

(Received 25/2/2018;

accepted $12 / 9 / 2018)$

\section{در اسات بالرنين الالكترونى المغزلى على التأثيرات الفزيو-كيميائية المميزة لبعض المضادات

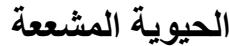 \\ صالح محمود عبده و سيف إبراهيم

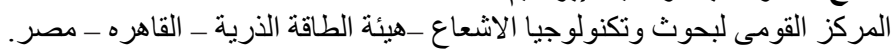

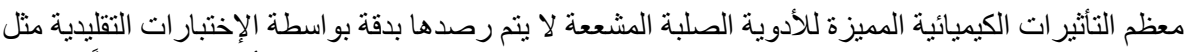



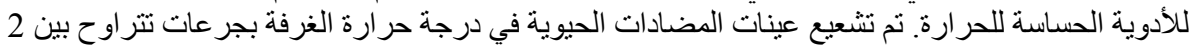

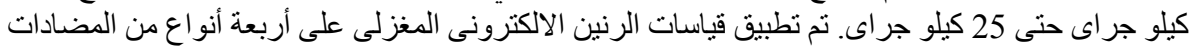
الحيوية (سبير اميسين و أمبسيلين ودائي الاسين و أموكسيسيللين).

أظهرت نتائج الرنين الإلكترونى المغزلى تأثثير الأشعاع و التخزين على طبيعة وتركيز الثقوق الغير حرة الثئ.

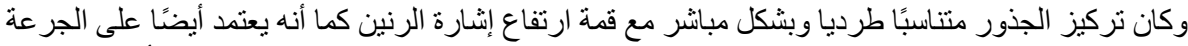

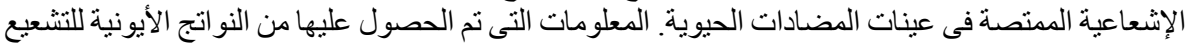
تحقق ميكانيكية الشقوق. هذه المعلومات ربما تستخدم لاستكشاف معالجة مثل هذه الأدوية بالتشعيع.
} 